\title{
THE GOOD, THE BAD, OR THE UGLY: EXAMINING IRANIAN EFL UNIVERSITY TEACHERS' AND GRADUATE STUDENTS' PERCEPTIONS OF PLAGIARISM
}

\author{
Zahra Alimorad \\ (zahra.alimorad@shirzu.ac.ir) \\ Shiraz University \\ PO Box 1585 Shiraz, Iran 71345
}

\begin{abstract}
This study attempted to investigate Iranian EFL teachers' and students' perceptions of plagiarism, the reasons for committing it, and the ways through which it can be resolved. To do so, a questionnaire was administered to a convenient sample of university teachers $(\mathrm{N}=9)$ and students $(\mathrm{N}=34)$. $\mathrm{Re}$ sults revealed that compared to their students, teachers reported greater amount of plagiarism in the writing samples given to them, which might imply that they were more strict in detecting plagiarism. In terms of the unfairness of plagiarism, both groups pointed out that plagiarists are primarily unfair to the original author because they take the credit that s/he really deserves. Regarding the reasons for doing plagiarism, too, both groups concurred that the most prominent reason is the students' inability to write scientifically. Finally, while students thought that this problem could be solved through open discussion and negotiation, teachers posited that open discussion as well as severe punishment methods could be used to solve the problem.
\end{abstract}

Keywords: Iranian teachers, university students, perceptions, plagiarism

DOI: http://dx.doi.org/10.15639/teflinjournal.v29i1/19-44

On the basis of international legislative penalties, it is still strongly believed that plagiarism is viewed as theft, and a plagiarist, violating copyright, is considered a thief (Sutherland-Smith, 2003). Accordingly, some Western universities have issued certain regulations to prevent such misconduct, 
The stakes are high in disciplinary actions against students accused of intramural offenses against authorship. Indeed, our institutions underline the seriousness of these proceedings by giving them the form, as well as some of the content, of legal actions for violations of copyright law (Jaszi, 1994, p. 29).

However, the perceptions held by English teachers are quite different from those of their colleagues in law (Sutherland-Smith, 2005). That is why a plethora of researchers attempted to investigate the issue from students' and teachers' viewpoint (Deckert, 1993; Myers, 1998; Pennycook, 1996 to name a few) or compared the perceptions held by these two groups (Bacha \& Bahous, 2010; Flowerdew \& Li, 2007a; Hard, Conway, \& Moran, 2006; Kwong, Ng, Mark, \& Wong, 2010; Li, 2007; Pickard, 2006; Rashidi, Rahimi, \& Dehghan, 2016; Wilkinson, 2009; Yazici, Yazici, \& Erdem, 2011). Some other studies were also conducted comparing the perceptions held by students at different academic stages (e.g., Chandrasegaran, 2000; Deckert, 1993; Hu \& Lei, 2012; Pittam, Elander, Lusher, Fox, \& Payne, 2009; Sun, 2009; Wheeler, 2009). Still, some other researchers tried to find ways to overcome plagiarism in students' writings by utilizing different teaching methods (Belcher, 1995; Bloch \& Chi, 1995; Braine, 1995; Howard, 1995, 1999). All such studies highlighted that different stakeholders hold diverse perceptions toward plagiarism. This strand of research has, in fact, investigated it from a socialization perspective which considered plagiarism a developmental phenomenon (Lei \& Hu, 2014) and viewed the mastery of legitimate intertextual practices an "enculturation task" (Ashworth, Freewood, \& Macdonald, 2003, p. 261).

Moreover, arguments have also been put forward that not only do different stakeholders have different perceptions, but also culture plays a determining role in this respect. To put it more clearly, it has been argued that while based on Western cultural norms and definitions, plagiarism is considered to be an academic misconduct which deserves punishment (Pecorari, 2002), it may be more reasonable to view it as "a cultural phenomenon that is conceptualized differently in different cultures" (Lei \& Hu, 2014, p. 2). An extreme version of this cultural perspective postulates that Western cultures condemn plagiarism while Asian cultures condone it (Sapp, 2002; Sowden, 2005). This extreme view, however, has been severely criticized by different scholars (Flowerdew \& Li, 2007b; Liu, 2005; Phan, 2006). Bloch (2008), by proposing a tempered cultural perspective, has convincingly argued that while different cultures may define plagiarism diversely, it does not mean that they will accept it; rather, 
they may have conceptualized it in a different way than that of the Western world. Results of recent studies have supported the tempered cultural perspective toward plagiarism (Hu \& Lei, 2012; Lei \& Hu, 2014; Wheeler, 2009). Such studies supported the conviction that although students and teachers of diverse cultural backgrounds may not hold the same or similar perceptions to those of Western scholars toward plagiarism, they have a punitive attitude toward it.

Based on the tempered cultural perspective, it may be envisaged that Iranian EFL teachers and learners, coming from an Asian background, hold a different conceptualization of the notion of plagiarism compared to Western researchers and scholars. Moreover, in the same cultural setting, teachers may have different perceptions toward it than their students. As a university professor, the present author has reviewed numerous research papers and M.A. and $\mathrm{Ph} . \mathrm{D}$. theses over recent years. What motivated this study was, in fact, the large number of plagiarism instances observed in Iranian EFL learners' academic writings. This situation drew the researcher's attention to the underlying assumptions and reasons behind such malpractice. To this aim, the present study intends to uncover Iranian EFL university teachers' and graduate students' perceptions toward plagiarism. Furthermore, it seeks to find the reasons behind it as well as the attitudes they hold toward plagiarism.

It seems that plagiarism had previously been an under-researched and almost neglected phenomenon in the context of Iran. This can be inferred by considering the limited number of studies on plagiarism before 2010 in this context. However, the pressure to either publish or perish in the context of Iranian universities (Bahadori, Izadi, \& Hoseinpourfard, 2012) has given rise to the detection of an increasing number of plagiarism instances in Iranian university students' and teachers' academic writings, which, in turn, has resulted in more systematic studies on the issue in this context. Some early studies (e.g., Amirkhani, Vahdat, \& Khezrian, 2010; Fealy, Biglari, \& Pezeshki Rad, 2012; Khamesan \& Amiri, 2011; Ojaghi, Keyvanara, Cheshmeh Sohrabi, \& Papi, 2011; Zafarghandi, Khoshroo \& Barkat, 2012) attempted to uncover the main reasons for plagiarizing from different perspectives. More recently, employing semi-structured interviews, Riasati and Rahimi (2013) examined a group of Iranian postgraduate students' viewpoints on their reasons for committing plagiarism. The participants reported a number of reasons including shallow understanding of the concept, lack of enough linguistic abilities, research and writing skills deficiencies, unfamiliarity with and lack of interest in the topics 
assigned to them as well as the pressures they felt from their family members and the society.

Rezanejad and Rezaei (2013) investigated Iranian students' perceptions toward and familiarity with plagiarism, the attitudes they held toward their professors about this issue, as well as their reasons for doing so. Results of their study revealed that students defined plagiarism diversely and considered it as using other people's words as if they were their own rather than using someone else's ideas without permission. Furthermore, they thought that instead of checking plagiarism, university professors mostly guess about who might have done it. Additionally, they reported different reasons for plagiarizing, the most important of which was the easiness of doing it.

In another study, Tahriri and Eslam-Navaz (2014) investigated Physical Education MA students' familiarity with the concept of plagiarism in their English academic writing. Their findings indicated that most of the participants were familiar with the concept of plagiarism; however, their knowledge was not sufficient since they just referred to the sources at the end of their papers. They mentioned some reasons for plagiarizing such as not receiving enough instruction, unfamiliarity with the concept as well as laziness.

More recently, Babaii and Nejadghanbar (2016) assessed the ability of Iranian students of Applied Linguistics in discerning plagiarism in writing, their perceptions toward its ethical aspects, the way they characterized plagiarists, and their reasons for plagiarism commitment. To this aim, they collected both quantitative and qualitative data of 156 graduate students of Applied Linguistics. Quantitative data analysis showed despite having some understanding of the concept, they displayed an inconsistent performance in recognizing plagiarism. With respect to the issues of ethics and fairness, they were more concerned with their own needs as well as the original writer's rights than the rights of their classmates, colleagues, or teachers. Unfamiliarity with the concept and nature of plagiarism were mentioned as the main reasons for committing plagiarism. Results of qualitative data analysis showed several reasons for committing plagiarism among students including lack of familiarity with plagiarism, deficient academic writing skills, teachers' careless and lenient behavior, students' lack of enough time, lazy and deceitful students, policies of the educational system, low language proficiency of the students, lack of familiarity with the subject of writing on the part of the students, and high expectations from students on the part of the teachers. 
In 2016, Amiri and Razmjoo, too, conducted a qualitative study to examine Iranian EFL learners' perceptions of plagiarism. However, they were mainly concerned with undergraduate students' perceptions. Analysis of semistructured interview data suggested that having a shallow understanding of the concept, the students committed plagiarism because of different reasons, namely, teachers' ignorance, students' limited research and writing skills, the pressure to prepare quality assignments, peer pressure and the ease of doing it.

Considering the above-mentioned studies, it seems that the majority of studies conducted on plagiarism in the context of Iran have investigated students' viewpoints, attitudes or perceptions toward plagiarism (Amiri \& Razmjoo, 2016; Amirkhani et al., 2010; Babaii \& Nejadghanbar, 2016; Fealy et al., 2012; Khamesan \& Amiri, 2011; Zafarghandi et al., 2012; Rezanejad \& Rezaei, 2013; Riasati \& Rahimi, 2013; Tahriri \& Eslam-Navaz, 2014) and few studies have attempted to examine the issue from teachers' viewpoint (Ojaghi et al., 2011). Moreover, a limited number of studies attempted to compare teachers' and students' perceptions of plagiarism. From among few studies which compared these two groups' perceptions, Rashidi et al. (2016) can be referred to as an example. They studied L2 graduate students and their teachers' perspectives about plagiarism and patchwriting as well as the way they worked for or against developing professional writing expertise. Results of their study showed that many graduate students used patchwriting while trying to write academic texts unintentionally and intuitively. Students' lack of confidence to write independently, lack of ability to paraphrase or fear of not being able to express the author's message completely, and attempting to get around plagiarism detection software were mentioned as reasons for committing plagiarism and patchwriting by the students. Nevertheless, both students and their teachers had negative attitudes toward patchwriting and believed that as a writing strategy, it does not lead to professional writing practices in a discipline. Furthermore, the authors claimed that the perpetual use of this practice may be the result of lack of enough instruction and feedback, which could highlight the importance of explicit teaching of the distinctions between paraphrasing and patchwriting.

A thorough review of the literature made it clear that the need for further research in this area is still strongly felt from both tempered cultural and socialization perspectives. To put it more clearly, more studies need to be done in Asian countries to shed more light on the differences in perceptions held by Asian teachers and students as compared with those of Western scholars. 
Moreover, additional studies need to compare teachers' and students' perceptions from a socialization perspective to see whether they are similar or different. This last question can serve as an awareness-raising endeavor helping teachers know their students' perceptions and make serious attempts to minimize any perceptual mismatches (Kumaravadivelu, 2003) to the extent possible. That being so, this study was going to identify the perceptions held by Iranian EFL university teachers and graduate students and to compare and contrast them to uncover any possible (mis)matches. To these ends, the study attempted to answer the following research questions,

1. In terms of discerning plagiarism instances, how do Iranian EFL university teachers perform compared to their graduate students?

2. How do the perceptions held by Iranian EFL university teachers compare with those of their graduate students regarding:

a. the unfairness of plagiarism,

b. reasons for committing plagiarism, and

c. the most effective ways to prevent plagiarism?

\section{METHOD}

A convenient sample of Iranian state university teachers and their graduate students, all majoring in TEFL (Teaching English as a Foreign Language), was recruited to participate in this study. The former group consisted of 9 university teachers (female $=3$, male $=6$ ) whose ages ranged from 33 to 50 years with an average of 42.33 years. Also, their teaching experience at university ranged from 5 to 25 years with an average of 14.22 years. The latter group were 34 (female $=20$, male $=14$ ) MA students at the same university. Their age range was 23-34, averaged 26.47 years. Both groups of participants were from the same ethnic background (Iranian) and all of them spoke Persian as the national and official language of their country.

To collect the necessary data, a questionnaire was designed and developed based on available questionnaires found in previous studies on plagiarism (Babaii \& Nejadghanbar, 2016; Deckert, 1993; Razera, 2011). As the first part of the questionnaire and inspired by the third section of Deckert's questionnaire (1993), the researcher herself composed ten sample in-text citations imagined to have been written by M.A. or Ph.D. students of TEFL in their academic term papers. These samples were, in fact, created based on the current researcher's experience of reviewing students' academic writings and detecting numerous 
plagiarism instances. The respondents were supposed to read the original paragraph and compare and contrast it with each of the ten samples, and then, decide whether each sample could be considered as a well-cited piece of writing or an instance of plagiarism. They were also asked to determine the extent to which plagiarism has been committed in each sample. For doing this, three options were provided: no plagiarism, some plagiarism, and a great amount of plagiarism. The second part of the questionnaire was taken from Deckert's. It consisted of seven 5-point Likert items in which the respondents were supposed to choose one of the five alternatives of strongly agree, agree, undecided, disagree, or strongly disagree. This section asked them about the unfairness of plagiarism; that is, when somebody plagiarizes something, to whom $\mathrm{s} / \mathrm{he}$ is unfair and why.

The rest of the questionnaire was taken from Razera (2011) with slight modifications. Section three attempted to elicit the participants' perceptions about reasons for resorting to plagiarism. In this section, 14 statements were enumerated and the participants were asked to choose up to four reasons among them. Also, space was provided for any additional comments and reasons not mentioned in that part. The last section asked them about the most effective ways to prevent plagiarism in which they were provided with 13 statements among which they could choose up to four. Again, space was allocated to further comments and suggestions. At the end of the questionnaire, the respondents were asked to mention other ideas and views on plagiarism if they wished so.

At the outset of the study, the researcher, who was the participating teachers' colleague and students' teacher, explained the purposes of the study to her colleagues and students and asked them to fill in the questionnaire. Given the fact that they were teachers and MA students of English, she decided to utilize the English version of the questionnaire. After seeking their willingness to cooperate as well as their consent and giving them assurance that their responses to questionnaire items would be kept confidential and would not lead to any adverse consequences, the researcher convinced the participants to take the time and fill out the questionnaire. They were also assured that there were no right or wrong answers and were asked to answer the items based on their own ideas as honestly as possible. They were given ample time to complete it while the researcher was present in the session to elaborate on the items or remove any potential ambiguities. 
After gathering the required data, the researcher made use of independent samples t-test to identify any possible differences between these two groups' performance while detecting plagiarism. To do this, the participants' responses to the first part of the questionnaire were rated as 2 (no plagiarism), 1 (some plagiarism), and 0 (a great amount of plagiarism). Then, these scores were added up to calculate a final score for the 10 writing samples for each participant's performance in terms of the extent to which they perceived each sample to be plagiarism. This means that for the first part of the questionnaire, the maximum score was 20 indicating no wrong uses of the source in the writing samples while the minimum could be 0 showing great amounts of plagiarism in all writing samples. These two sets of scores (teachers' and students' scores) were compared using descriptive statistics as well as independent samples t-test. In addition, to analyze the rest of data, the researcher utilized descriptive statistics such as frequencies and percentages.

\section{FINDINGS AND DISCUSSION}

In this section, each of the research questions will be answered on the basis of the findings obtained from the gathered data.

\section{In terms of discerning plagiarism instances, how do Iranian EFL universi- ty teachers perform compared to their graduate students?}

To see how these university teachers and their graduate students discerned plagiarism instances and how their performances compared, an independent samples t-test was run. Tables 1 and 2 present the descriptive statistics as well as the results of the t-test.

Table 1. Descriptive Statistics

\begin{tabular}{llll}
\hline Participants & N & Mean & SD \\
\hline Teachers & 9 & 7.11 & 3.58 \\
\hline Students & 34 & 11.14 & 3.54
\end{tabular}

As can be seen in Table 1, the mean of teachers' plagiarism detection (mean = $7.11, \mathrm{SD}=3.58)$ is smaller than that of the students $($ mean $=11.14, \mathrm{SD}=3.54)$ indicating that from these teachers' point of view, the samples were considered as containing more plagiarism compared to their students' perceptions. 
Alimorad, Teachers' and Students' Perceptions of Plagiarism 27

Table 2. Independent Samples t-test

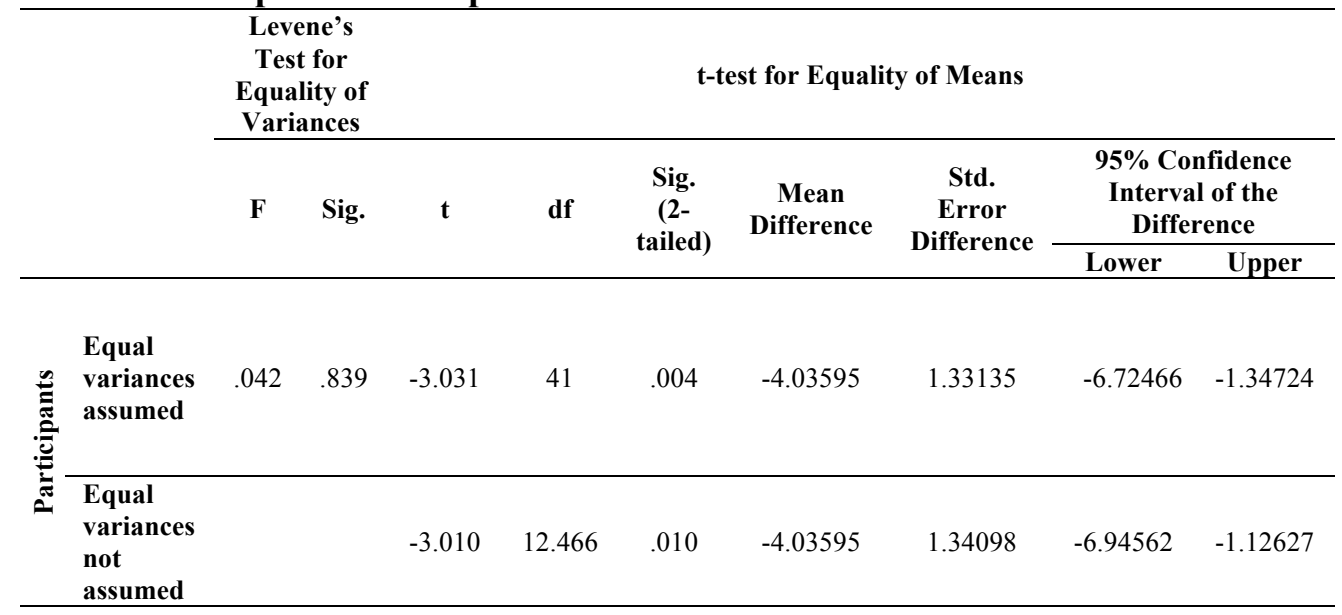

As Table 2 shows, Levene's test for equality of variances was .839 which was larger than .05 pointing out that the variance of scores for the two groups was the same. Therefore, the assumption of equal variances was met. After checking this assumption, we could see that the t-test result was statistically significant at .01 level of significance $(\mathrm{t}(41)=-3.031, \mathrm{p}=.004)$. The magnitude of this difference in the means (mean difference $=-4.03595$ ) was also very large considering eta squared which was .18 (Cohen as cited in Pallant, 2011). This effect size pointed out that 18 percent of the variance in plagiarism detection scores could be explained by the participants' occupation; that is, their being either teachers or students.

This finding shows that compared to their graduate students, Iranian EFL university teachers are more severe at discerning plagiarism. This means what is considered plagiarism by the teachers may not be viewed as misappropriation of other people's words or ideas by the students, which, in turn, highlights the existence of a mismatch between these two groups' perceptions. This finding corroborates Lei and Hu's (2014) idea of considering plagiarism as a developmental phenomenon and contributes to our understanding of viewing the mastery of legitimate intertextual practices an enculturation task as postulated by Ashworth et al. (2003). The same finding also lends support to what Zafarghandi et al. (2012) found in their study. As suggested by their findings, lack of 
enough knowledge of plagiarism on the part of the students could be one of the reasons for prevalence rates of it in the context of Iran. In line with this finding, they also found that plagiarism detection could be a demanding and challenging task for students even up to the end of their academic lives. Moreover, Tahriri and Eslam-Navaz (2014) and Babaii and Nejadghanbar (2016), too, found insufficient knowledge of plagiarism as well as inconsistent performance in recognizing it on the part of Iranian students, which are in line with this finding.

Regarding the unfairness of plagiarism, how do the perceptions held by Iranian EFL university teachers compare with those of their graduate students?

To find out how the present participants perceived the unfairness of plagiarism and to whom, they believed, the plagiarist could be unfair, the means and standard deviations of all items were calculated and then, a series of independent samples t-tests was run to see whether teachers' and students' perceptions were statistically different from each other. Given that multiple t-tests were run simultaneously, a Bonfferroni adjustment was applied to avoid making Type I error. To do that, the traditional alpha level (i.e., 0.05) was divided by 7 and a more stringent alpha level (i.e., 0.007) was set as the level of significance in this part; that is, alpha values lower than or equal to 0.007 were considered statistically significant. Results of these analyses are reported in Table 3.

Table 3. Unfairness of Plagiarism as Perceived by Teachers and Students

\begin{tabular}{|c|c|c|c|c|c|}
\hline Item & & Mean & SD & $t$ & Sig. \\
\hline \multirow{2}{*}{$\begin{array}{l}\text { 1. S/he is unfair to the college because the } \\
\text { educational goals of the college can never } \\
\text { be reached if students just copy } \\
\text { information. }\end{array}$} & Ts & 4.55 & .52 & 1.684 & .10 \\
\hline & Ss & 3.97 & .99 & & \\
\hline \multirow{2}{*}{$\begin{array}{l}\text { 2. S/he is unfair to her/himself } \text { because the } \\
\text { teacher might recognize what } \mathrm{s} / \text { he did } \\
\text { and punish or embarrass him/her in front } \\
\text { of other students. }\end{array}$} & Ts & 3.44 & 1.58 & -.471 & .64 \\
\hline & Ss & 3.64 & 1.01 & & \\
\hline
\end{tabular}


Alimorad, Teachers' and Students' Perceptions of Plagiarism 29

\begin{tabular}{clllll}
\hline Item & & Mean & SD & t & Sig. \\
\hline & Ts & 4.55 & 1.01 & 1.299 & .20
\end{tabular}

3. S/he is unfair to her/himself because $\mathrm{s} /$ he is not learning much when $\mathrm{s} /$ he just copies another person's writing.

\begin{tabular}{llllll} 
& Ss & 3.97 & 1.24 & & \\
\hline & Ts & 3.44 & 1.50 & -1.37 & .19
\end{tabular}

4. S/he is unfair to her/himself because $\mathrm{s} /$ he is not being her/himself. Rather, s/he is pretending to be better than $\mathrm{s} / \mathrm{he}$ is, and that makes him/her feel uncomfortable.

5. S/he is unfair to the writer of the

original passage because $\mathrm{s} / \mathrm{he}$ is taking the credit that the writer really deserves for the words and ideas.

\begin{tabular}{llllll} 
Ss & 4.67 & .63 & & \\
\hline & Ts & 4.44 & .72 & 1.483 & .14
\end{tabular}

6. S/he is unfair to his/her classmates

because most of them worked harder by writing in their own words, but s/he mainly copied and yet gets the same or even a better grade.

\begin{tabular}{lllll} 
Ss & 4.17 & .99 & & \\
\hline Ts & 4.88 & .33 & .958 & .34
\end{tabular}

\begin{tabular}{llllll} 
Ss & 3.82 & 1.19 & & \\
\hline & Ts & 4.77 & .44 & 1.860 & .07
\end{tabular}

7. S/he is unfair to her/his teacher because the teacher is trying to teach him/her to write well, but $\mathrm{s} /$ he is not cooperating.

\section{Ts: Teachers, Ss: Students}

Ss $\quad 4.17 \quad .93$

As the findings reported in Table 3 suggest, from both the teachers' and students' points of view, a plagiarist could be regarded as unfair to the writer of the original passage because $\mathrm{s} / \mathrm{he}$ is taking the credit that the writer really deserves for the words and ideas. A closer look at the means and standard deviations for the two groups (Ts: Mean=4.88, $\mathrm{SD}=.33$; Ss: Mean=4.67, $\mathrm{SD}=.63$ ) as well as the $\mathrm{t}$ value $(\mathrm{t}=.958$, Sig. $=.34)$ reveals that both teachers and students placed the greatest emphasis on the original author's rights. Both groups also ranked a plagiarist's being unfair to the teacher because of the students' not co- 
operating with him/her as the second most important item (Ts: Mean=4.77, $\mathrm{SD}=.44$; Ss: Mean=4.17, $\mathrm{SD}=.93, \mathrm{t}=1.860$, Sig.=.07). However, the students attached the same level of importance to a plagiarist's being unfair to him/herself because of not being him/herself too (Item 4, Mean=4.17, SD=.99). For the teachers, items 1 (Mean=4.55, $\mathrm{SD}=.52)$ and 3 (Mean=4.55, $\mathrm{SD}=1.01)$ stood as the third most important ones which pointed out the unfairness to college as well as the plagiarist him/herself because of not learning what they should learn as being of equal importance. Nevertheless, a look at the standard deviations of these two items makes it clear that these teachers more unanimously agreed that the rights of a college violated by some students' plagiarizing could be more significant. Surprisingly, the same two items, that is, 1 (Mean=3.97, $\mathrm{SD}=.99$ ) and 3 (Mean=3.97, $\mathrm{SD}=1.24$ ) were considered as the third most important ones by the students too. Standard deviations too conspicuously point to a more unanimous decision among students about the importance of unfairness to college as compared to that of the plagiarist's rights. Furthermore, according to the teachers, item 6 was the fourth important item dealing with the rights of a plagiarist's classmates (Mean=4.44, $\mathrm{SD}=.72$ ) and the fact that fair evaluation could be questionable when some students engage in plagiarism. Item 2 (Ts: Mean=3.44, SD=1.58; Ss: Mean=3.64, SD=1.01) which dealt with the idea of punishment and embarrassment as a result of committing plagiarism was given the least importance by both teachers and students. However, as the $t$ and significance values indicate, none of the differences among teachers' and students' means were statistically significant, which provides positive evidence for the match between these two groups' perceptions regarding the unfairness of plagiarism.

This finding partly supports Babaii and Nejadghanbar's (2016) results which suggested that Iranian students were concerned with the original writer's rights. Nevertheless, it contradicts their findings in that the current students placed their own rights as well as the right of the teacher in the second order of importance. Viewing the same finding from another perspective provides positive evidence in support of a correspondence between teachers' and students' perceptions toward the unfairness of plagiarism, which can partially lend support to what Rashidi et al. (2016) found in their study. Findings of their study also pointed out a match between teachers' and students' ideas about plagiarism in that both groups held negative attitudes toward this malpractice. 
Alimorad, Teachers' and Students' Perceptions of Plagiarism 31

Regarding reasons for committing plagiarism, how do the perceptions held by Iranian EFL university teachers compare with those of their graduate students?

Findings concerning this research question are presented in Table 4.

Table 4. The Most Common Reasons for Plagiarism from Teachers' and Students' Point of Views

\begin{tabular}{ccccc}
\hline Item & $\boldsymbol{f}$ & $\mathbf{\%}$ \\
\hline Ts & 1 & 11.11
\end{tabular}

The student does not understand that studying is aimed at independent and critical thinking.

\begin{tabular}{rlrr} 
& Ss & 6 & 17.64 \\
\hline & Ts & 1 & 11.11
\end{tabular}

The student has doubts regarding and/or underestimates his/her own abilities.

\begin{tabular}{lll} 
Ss & 9 & 26.47 \\
\hline Ts & 2 & 22.22
\end{tabular}

The student feels that she/he cannot express anything as well in his/her own words.

\begin{tabular}{llll} 
& Ss & 14 & 41.17 \\
\hline & Ts & 7 & 77.77
\end{tabular}

The student does not know how to write scientifically.

\begin{tabular}{ccc} 
Ss & 21 & 61.76 \\
\hline Ts & 2 & 22.22
\end{tabular}

The student lacks knowledge about what is allowed and what is not allowed.

\begin{tabular}{llll} 
& Ss & 12 & 35.29 \\
\hline & Ts & 2 & 22.22
\end{tabular}

The course demands are too high.

\begin{tabular}{lcr} 
Ss & 10 & 29.41 \\
\hline Ts & 2 & 22.22
\end{tabular}

There is a competition among students with respect to grades.

\begin{tabular}{llll} 
& Ss & 4 & 11.76 \\
\hline & Ts & 4 & 44.44
\end{tabular}

The student wants to pass the course at any cost (performance requirements from financial supplier, near graduation).

Ss $\quad 14 \quad 41.17$




\begin{tabular}{lllr}
\hline \multicolumn{1}{c}{ Item } & & $\boldsymbol{f}$ & $\mathbf{\%}$ \\
\hline \multicolumn{1}{c}{ The student believes plagiarism to be worthwhile; for } & 2 & 22.22 \\
$\begin{array}{l}\text { example, it results in better grades. } \\
\text { Ts }\end{array}$ & Ss & 6 & 17.64 \\
\hline & Ts & 3 & 33.33
\end{tabular}

The student lacks motivation.

\begin{tabular}{ccc} 
Ss & 9 & 26.47 \\
\hline Ts & 0 & 0
\end{tabular}

The student lacks interest in the topic of the study.

\begin{tabular}{lll} 
Ss & 6 & 17.64 \\
\hline Ts & 7 & 77.77
\end{tabular}

The student sees plagiarism as an easy way out especially today, with the spread of computers and the Internet.

\begin{tabular}{llll} 
& Ss & 14 & 41.17 \\
\hline & Ts & 1 & 11.11
\end{tabular}

The student lacks time.

\begin{tabular}{llll} 
& Ss & 8 & 23.52 \\
\hline & Ts & 4 & 44.44 \\
The student is lazy. & & & \\
& Ss & 5 & 14.70 \\
\hline
\end{tabular}

Ts: Teachers, Ss: Students

A close inspection of the findings reported in Table 4 makes it clear that from both teachers' and students' points of view, lack of knowledge of how to write scientifically on the part of students (Ts: $f=7, \mathrm{p}=77.77 \%$; Ss: $f=21$, $\mathrm{p}=61.76 \%$ ) could be considered as the main reason for engaging in plagiarism by university students. However, although the spread of computers and the internet was thought to be as important as lack of knowledge from teachers' perspective $(f=7, \mathrm{p}=77.77 \%)$, for students, this reason was of equal importance to passing the course at any cost and the feeling that they are not capable of expressing the ideas as well as the original author's words $(f=14, \mathrm{p}=41.17 \%)$. For teachers, the idea of some outside forces which make the students want to pass the course at any cost along with students' being lazy stood as the second most common reason for students' committing plagiarism $(f=4, \mathrm{p}=44.44 \%)$. Furthermore, lack of motivation $(f=3, \mathrm{p}=33.33 \%)$ was reported as the third reason while students' inability to express ideas as well as the original writers have expressed them, their lack of knowledge of what is and is not allowed, high 
course demands, competition among students to get better grades, and getting better grades by committing plagiarism $(f=2, \mathrm{p}=22.22 \%)$ were all ranked the fourth most common reasons for students' plagiarism by these teachers. Not understanding the real purpose of studying (i.e., independent and critical thinking), underestimating their own abilities, and lack of time $(f=1, \mathrm{p}=11.11 \%)$ were mentioned as the fifth reasons while, from these teachers' point of view, lack of interest in the topic of the study was not regarded as a reason for students' committing plagiarism.

Students' perceptions were slightly different; that is, for them, lack of knowledge of what is and is not allowed $(f=12, \mathrm{p}=35.29 \%)$ and high course demands $(f=10, \mathrm{p}=29.41 \%)$ were the third and fourth most common reasons which were the fourth reason from teachers' viewpoint. Moreover, the students thought that underestimating their own abilities along with lack of motivation $(f=9, \mathrm{p}=26.47 \%)$ were the fifth ranking reasons while for teachers, lack of motivation on the part of students was considered to be a more common reason as compared with an underestimation of their abilities. While, for teachers, lack of time was the fifth ranking reason, for students, it was the sixth ranking one. Students referred to their not understanding the main purpose of studying, getting better grades as a result of plagiarizing, and lack of interest in the topic of the study $(f=6, p=17.64 \%)$ as the seventh most common reasons. This is different from what teachers mentioned in that from teachers' perspective, lack of interest in the topic did not receive any credit while from students' point of view, it could be one reason for committing plagiarism. This finding partially lends support to Riasati and Rahimi's (2013) result which suggested that lack of interest in the topics assigned to students could be one of the reasons contributing to plagiarism. Another mismatch between these two groups' perceptions could be found in their ideas regarding the students' laziness. That is, while teachers believed that students' being lazy was the second ranking reason, students referred to it as the eighth reason. Additionally, although competition to get better grades was the least common reason from students' viewpoint $(f=4$, $\mathrm{p}=11.76 \%)$, it was the fourth common one from teachers' perspective ( $f=2$, $\mathrm{p}=22.22 \%$ ).

As is evident, both groups reported students' limited knowledge of scientific writing as the main reason for committing plagiarism, which is in sharp contrast to what Rezanejad and Rezaei (2013) concluded in their study. Results of their study pointed to the easiness of engaging in plagiarism as the main reason for doing it, which was not supported by the findings of the current study. 
The same finding partly supports what Amiri and Razmjoo (2016) found in their study. They came to the conclusion that students' limited research and writing skills as well as the pressure to prepare quality assignments could be the main reasons although they referred to the ease of committing plagiarism as another reason which is not in agreement with the current findings. Babaii and Nejadghanbar's (2016) findings, too, indicated that students' deficient academic writing skills could be a reason for plagiarism, which is in agreement with the findings of the current study. Rashidi et al. (2016) also pointed to students' lack of confidence to write independently as one of the reasons, which can be explained by their inability to write scientifically. All in all, however, although some reasons were shared by both participating groups in this study, some areas of mismatch could be found between their perceptions of the most common reasons for plagiarizing which merit further examination and investigation by other researchers in the future.

\section{Regarding the most effective ways to prevent plagiarism, how do these two groups' perceptions compare?}

Table 5 shows the frequency and percentage of responses given by teachers and students to each of the items of the questionnaire regarding the most effective ways to prevent plagiarism.

Table 5. The Most Effective Ways to Prevent Plagiarism as Perceived by Teachers and Students

\begin{tabular}{cccc}
\hline Item & $\boldsymbol{f}$ & $\mathbf{\%}$ \\
\hline Ts & 1 & 11.11
\end{tabular}

Assignments should be formulated differently.

\begin{tabular}{llc} 
Ss & 3 & 8.82 \\
\hline Ts & 5 & 55.55
\end{tabular}

Teachers should have more time to develop good exams and tasks that require critical thinking and analysis and not just to test factual knowledge.

\begin{tabular}{llr} 
Ss & 12 & 35.29 \\
\hline & 3 & 33.33
\end{tabular}

Students should get better training in the type of assignments where plagiarism usually occurs to give them better self-esteem.

Ss $\quad 13 \quad 38.23$


Alimorad, Teachers' and Students' Perceptions of Plagiarism 35

\begin{tabular}{ccccc}
\hline Item & $\boldsymbol{f}$ & $\mathbf{\%}$ \\
\hline & Ts & 4 & 44.44
\end{tabular}

Students should have better knowledge about academic writing, for example, by attending a course in academic writing.

\begin{tabular}{llll} 
Ss & 22 & 64.70 \\
\hline & Ts & 3 & 33.33
\end{tabular}

Students should learn what is allowed and not allowed through education and open discussions.

\begin{tabular}{cccc} 
& Ss & 15 & 44.11 \\
\hline & Ts & 1 & 11.11
\end{tabular}

Teachers should learn what is allowed and not allowed through education and open discussions.

\begin{tabular}{llll} 
Ss & 4 & 11.76 \\
\hline & Ts & 2 & 22.22
\end{tabular}

Students should be informed at every examination where there is a risk of plagiarism.

\begin{tabular}{llll} 
Ss & 7 & 20.58 \\
\hline & Ts & 6 & 66.66
\end{tabular}

Teachers should openly discuss plagiarism with students.

\begin{tabular}{rcccc} 
& Ss & 16 & 47.05 \\
\hline & Ts & 6 & 66.66
\end{tabular}

The penalty for those who committed should be severe.

\begin{tabular}{lllll} 
& Ss & 8 & 23.52 \\
\hline & Ts & 4 & 44.44
\end{tabular}

Electronic plagiarism detection tools should be used.

\begin{tabular}{lll} 
Ss & 6 & 17.64 \\
\hline Ts & 2 & 22.22
\end{tabular}

Students should be informed that their work will be checked for plagiarism.

\begin{tabular}{cccc} 
Ss & 10 & 29.41 \\
\hline & Ts & 0 & 0
\end{tabular}

The students' course workload should be reduced.

\begin{tabular}{lll} 
Ss & 8 & 23.52 \\
\hline Ts & 1 & 11.11
\end{tabular}

Students should receive proper instructions on writing assignments in time so that time pressure is avoided.

Ts: Teachers, Ss: Students

$\begin{array}{lll}\text { Ss } & 8 & 23.52\end{array}$


As shown in Table 5, from these teachers' point of view, the most effective ways to prevent plagiarism were teachers' open discussion of plagiarism with students $(f=6, \mathrm{p}=66.66 \%)$ as well as administering severe punishment for those who commit plagiarism $(f=6, \mathrm{p}=66.66 \%)$. Students, on the other hand, thought that letting students have better knowledge of academic writing through attending relevant courses could be the main solution for avoiding plagiarism $(f=22$, $\mathrm{p}=64.70 \%$ ). Allowing teachers to have more time to develop good exams and tasks that require critical thinking and analysis and not just to test factual knowledge $(f=5, \mathrm{p}=55.55 \%)$ was the second solution suggested by the teachers which was the fifth ranking item from the students' perspective $(f=12$, $\mathrm{p}=35.29 \%$ ). As the third ranking items, from teachers' point of view, improving students' knowledge of academic writing and using electronic plagiarism detection tools were considered as equally important actions $(f=4, \mathrm{p}=44.44 \%)$ which could be taken to prevent plagiarism. Interestingly, these teachers did not suggest reducing students' workload as a workable solution for solving this problem although students believed that this could contribute to tackling the problem $(f=8, \mathrm{p}=23.52 \%)$. This mismatch might be more serious than what it really appears because, in line with Babaii and Nejadghanbar's (2016) findings and as mentioned by the student sample in this study, teachers' high expectations from students could be one of the contributing factors which might be partially solvable by reducing students' workload. Open discussion of plagiarism $(f=16$, $\mathrm{p}=47.05 \%)$ and teaching students what is allowed and not allowed $(f=15$, $\mathrm{p}=44.11 \%$ ) were mentioned by the students as the second and third suggestions. After these, giving students more training $(f=13, \mathrm{p}=38.23 \%)$ and teachers more time $(f=12, \mathrm{p}=35.29 \%)$ were the next two items chosen by the present students more frequently. Although the teachers quite frequently suggested the use of plagiarism detection tools $(f=4, \mathrm{p}=44.44 \%)$, from students' viewpoint, it could not be a viable solution $(f=6, \mathrm{p}=17.64 \%)$. Finally, formulating assignments differently was the least referred to item by the students $(f=3, \mathrm{p}=8.82 \%)$.

Results of this part revealed that while students thought that this problem could best be resolved by providing students with further training and relevant courses, teachers seemed to be harsher suggesting more severe penalties and the use of plagiarism detection tools, in addition to training courses, as effective ways to prevent plagiarism. These diverse ideas might be attributable to these two groups' different perceptions. It seems that students perceived plagiarism as more of an unintentional act which could be solved through negotiation and training while teachers thought that it could be either intentional or unin- 
tentional. That is why they perceived that sometimes it merited severe punishment. This finding lends support to what Ojaghi et al. (2011) found in the context of Iran. As they concluded, Esfahan University teachers, like their peers in this study, thought that punishment and criticism would denaturalize this misconduct in the eyes of the students so that they would not resort to it. Rezanejad and Rezaei (2013), on the other hand, pointed to the crucial role teachers can play in this regard and suggested that plagiarism be checked by the teachers. The same concern was also mentioned by Babaii and Nejadghanbar (2016) who reported teachers' lenient and careless behavior as one of the major causes of plagiarism. In a similar vein, Amiri and Razmjoo (2016) pointed to teachers' ignorance as a determining factor in this respect. Furthermore, considering students' lack of enough instruction and feedback as one of the major reasons contributing to plagiarism, Rashidi et al. (2016) suggested explicit teaching of these issues as a solution to solve this problem. Considering all these findings, it seems that there is no unanimous consensus regarding the most effective ways to prevent plagiarism in that there is no generally accepted definition for this term. Therefore, it is highly recommended that other researchers in different parts of the world attempt to conduct more in-depth studies of teachers' and students' perceptions of plagiarism from different angles to shed more light on this vital issue.

\section{CONCLUSIONS}

This study intended to examine Iranian EFL university teachers' and their graduate students' perceptions of plagiarism. Results of the study suggested that in terms of discerning plagiarism instances, university teachers seemed to be more severe in comparison to their students because they reported greater amount of plagiarism in the writing samples. This finding indicates that the perceptions held by teachers toward what is considered misappropriation of others' ideas or words are different from those held by their students.

Furthermore, it was found that both teachers and students thought by committing plagiarism, a person is first and foremost unfair to the original writer because $\mathrm{s} / \mathrm{he}$ is taking the credit that the writer deserves. This finding shows that contrary to the extreme cultural perspective put forward by some scholars (Sapp, 2002; Sowden, 2005), Asian people, including Iranian researchers, do not condone plagiarism but condemn it severely. Among the reasons mentioned by these teachers and students, lack of knowledge of how to 
write scientifically was ranked first, which points out what drives the students to copy other people's words or ideas is mostly their insufficient knowledge of scientific writing rather than their deliberate attempt to abdicate responsibility. Finally, the findings of the last part of the questionnaire suggested while students thought that this problem could be solved through open discussion, negotiation, and training, teachers recommended open discussion and negotiation as well as more severe punishment methods.

The findings of this study can deepen our understanding of plagiarism from both theoretical and pedagogical perspectives. Regarding the former, it can convincingly be argued that it is best not to consider the surging number of plagiarism instances in Iranian EFL students' academic writings as evidence in support of their being dishonest or deceitful or their encouraging or preferring such misconduct; rather, in the same way as their peers in Western countries, they condemn plagiarism by holding negative attitudes toward those who plagiarize. Therefore, what is obvious is that the extreme cultural view is undoubtedly rejected while the tempered cultural perspective is supported by these findings.

It was also found that university teachers were able to detect more plagiarism instances compared to their students which can be interpreted in the light of the socialization perspective toward plagiarism according to which, plagiarism is a developmental process which can be learned and mastered gradually by the students. All these findings, however, do not justify the occurrence of plagiarism in Iranian EFL university teachers' and graduate students' academic writings; hence, they need to pay more careful attention to their academic productions and try not to commit plagiarism since, even if done unknowingly and unintentionally, plagiarism instances found in their writings may lead to their losing face in the global discourse community. Moreover, the majority of their articles, in spite of being novel and informative, may be rejected by international journals because of plagiarism.

With respect to the latter, university teachers need to know that high course demands and time limitations might make the students resort to plagiarism to carry out their academic duties. Although more serious punishment methods may improve the situation, they may only serve as a temporary solution. Therefore, more permanent and lasting solutions are needed to alleviate the problem altogether. To reach this goal, students need to be made aware of what plagiarism really means to their peers in other parts of the world and how it may be interpreted by them because if they are made aware of the true uneth- 
ical and immoral meanings attached to this misconduct, they may less engage in doing it. Additionally, training sessions in which students are taught what plagiarism means and how to avoid committing it might prove helpful and effective.

Like all other studies, this study also suffers from certain limitations which restrict the generalizability of its findings. The first and foremost limitation is the selection of the participants which, because of practical problems, could not be done randomly. Other researchers may be able to replicate the study using probability sampling procedures to either refute or confirm the findings of this study in the future. Another limitation is the size of the sample which may create certain problems while interpreting the findings of the study. Future studies can be done using a larger sample of university teachers and graduate students to give a more vivid picture of what their perceptions of plagiarism are. Moreover, this study made use of a single instrument for collecting data. Other researchers can use different types of data gathering tools such as interviews, observations, documents and questionnaires to triangulate the data and reach more valid and reliable conclusions. Additionally, more sophisticated data analysis procedures can be used to find out how these two groups' perceptions compare. Plagiarism can also be viewed from a more in-depth point of view by examining the way it is individually and socially constructed during the passage of time through conducting longitudinal qualitative studies. Hence, investigating the role of different factors in the macro and micro contexts in which the students live and study can be a fruitful area of inquiry in the future. Therefore, besides quantitative research, we call for more qualitative and mixedmethod studies on plagiarism to see how it is constructed, deconstructed or reconstructed while the individuals are acting, reacting and interacting in their discourse communities as well as the society at large.

\section{REFERENCES}

Amiri, F., \& Razmjoo, S. A. (2016). On Iranian EFL undergraduate students' perceptions of plagiarism. Journal of Academic Ethics, 14(2), 115-131.

Amirkhani, A. H., Vahdat, D., \& Khezrian, S. (2010). Ertebat beine akhlaghe Interneti va panj olgooye shakhsiatie daneshjooyan [The relationship between internet ethics and the big five personality traits of university students]. Faslnameye Akhlagh dar Oloom va Fanavari, 5(3), 57-66. 
Ashworth, P., Freewood, M., \& Macdonald, R. (2003). The student lifeworld and the meanings of plagiarism. Journal of Phenomenological Psychology, 34(2), 257-278.

Babaii, E., \& Nejadghanbar, H. (2016). Plagiarism among Iranian graduate students of language studies: Perspectives and causes. Ethics \& Behavior, 27(3), 1-19.

Bacha, N. N., \& Bahous, R. (2010). Student and teacher perceptions of plagiarism in academic writing. Writing \& Pedagogy, 2(2), 251-280.

Bahadori, M., Izadi, M., \& Hoseinpourfard, M. (2012). Plagiarism: Concepts, factors and solutions. Iranian Journal of Military Medicine, 14(3), 168177.

Belcher, D. (1995). Writing critically across the curriculum. In D. Belcher, \& G. Braine (Eds.), Academic writing in a second language: Essays on research and pedagogy (pp. 135-154). Norwood, NJ: Ablex.

Bloch, J. (2008). Plagiarism across cultures: Is there a difference? In C. Eisner \& M. Vicinus (Eds.), Originality, imitation, and plagiarism: Teaching writing in the digital age (pp. 219-230). Ann Arbor: University of Michigan Press.

Bloch, J., \& Chi, L. (1995). A comparison of the use of citations in Chinese and English academic discourse. In D. Belcher, \& G. Braine (Eds.), Academic writing in a second language: Essays on research and pedagogy (pp. 231-274). Norwood, NJ: Ablex.

Braine, G. (1995). Writing in the natural sciences and engineering. In D. Belcher, \& G. Braine (Eds.), Academic writing in a second language: Essays on research and pedagogy (pp. 113-134). Norwood, NJ: Ablex.

Chandrasegaran, A. (2000). Cultures in contact in academic writing: Students' perceptions of plagiarism. Asian Journal of English Language Teaching, 10, 91-113.

Deckert, G. D. (1993). Perspectives on plagiarism from ESL students in Hong Kong. Journal of Second Language Writing, 2(2), 131-148.

Fealy, S., Biglari, N., \& Pezeshki Rad, G. (2012). Attitudes and behaviors of students in Faculty of Agriculture, Tarbiat Modarres University toward 
plagiarism. Faslnameh Pazhoohesh va Barname Rizi dar Amoozeshe Ali, $18(3), 133-151$.

Flowerdew, J., \& Li, Y. (2007a). Language re-use among Chinese apprentice scientists writing for publication. Applied Linguistics, 28(3), 440-465.

Flowerdew, J., \& Li, Y. (2007b). Plagiarism and second language writing in an electronic age. Annual Review of Applied Linguistics, 27, 161-183.

Hard, S. F., Conway, J. M., \& Moran, A. C. (2006). Faculty and college student beliefs about the frequency of student academic misconduct. The Journal of Higher Education, 77(6), 1058-1080.

Howard, R. M. (1995). Plagiarisms, authorships and the academic death penalty. College English, 57(7), 788-806.

Howard, R. M. (1999). Standing in the shadow of giants: Plagiarists, authors, collaborators. Stamford: Ablex.

Hu, G., \& Lei, J. (2012). Investigating Chinese university students' knowledge of and attitudes toward plagiarism from an integrated perspective. Language Learning, 62(3), 813-850.

Jaszi, P. (1994). On the author effect: Contemporary copyright and collective creativity. In P. Jaszi, \& M. Woodmansee (Eds.), The construction of authorship: Textual appropriation in law and literature (pp. 29-56). Durham: Duke University Press.

Khamesan, A., \& Amiri, M. A. (2011). Barresiyeh taghallobe tahsili dar miane danshjooyane dokhtar va pesar [Studying educational plagiarism among male and female students]. Faslnameye Akhlagh dar Oloom va Fanavari, 6(1), 53-61.

Kumaravadivelu, B. (2003). Beyond methods: Macrostrategies for language teaching. New Haven and London: Yale University Press.

Kwong, T., Ng, H., Mark, K., \& Wong, E. (2010). Students' and faculty's perception of academic integrity in Hong Kong. Campus-Wide Information Systems, 27(5), 341-355.

Lei, J., \& Hu, G. (2014). Chinese university EFL teachers' perceptions of plagiarism. Higher Education, 70(3), 551-565. 
Li, Y. (2007). Apprentice scholarly writing in a community of practice: An "intraview" of an NNES graduate student writing a research article. TESOL Quarterly, 41(1), 55-79.

Liu, D. (2005). Plagiarism in ESOL students: Is cultural conditioning truly the major culprit? ELT Journal, 59(3), 234-241.

Myers, S. (1998). Questioning author(ity): ESL/EFL, science, and teaching about plagiarism. TESL-EJ: Teaching English as a Second or Foreign Language, 3(2), 1-21.

Ojaghi, R., Keyvanara, M., Cheshmeh Sohrabi, M., \& Papi, A. (2011). Tahlile asibshenasiye taghallob va serghate elmi: Bar asase yek tahghighe keifi [Analyzing the problems of cheating and plagiarism: Based on a qualitative study]. Majaleh Irani Amoozesh dar Oloome Pezeshki, 11(9), 1063-1073.

Pallant, J. (2011). SPSS survival manual: A step by step guide to data analysis using SPSS (4th ed.). Crows Nest, NSW: Allen \& Unwin.

Pecorari, D. (2002). Original reproductions: An investigation of the source use of postgraduate second language writers (Doctoral dissertation, University of Birmingham, Birmingham, UK).

Pennycook, A. (1996). Borrowing others' words: Text, ownership, memory and plagiarism. TESOL Quarterly, 30(2), 201-230.

Phan, L. H. (2006). Plagiarism and overseas students: Stereotypes again? ELT Journal, 60(1), 76-78.

Pickard, J. (2006). Staff and student attitudes to plagiarism at University College Northampton. Assessment \& Evaluation in Higher Education, $31(2), 215-232$.

Pittam, G., Elander, J., Lusher, J., Fox, P., \& Payne, N. (2009). Student beliefs and attitudes about authorial identity in academic writing. Studies in Higher Education, 34(2), 153-170.

Rashidi, N., Rahimi, M., \& Dehghan, F. (2016). Perspectives of L2 graduate students and their professors about students' academic writing practices: Patchwriting or plagiarism? English Language Teaching, 3(1), 95-110. 
Razera, D. (2011). Awareness, attitude, and perception of plagiarism among students and teachers at Stockholm University (Master's thesis, Stockholm University, Sweden). Retrieved from http://www.diva-portal.org/smash/ get/diva2:432681/FULLTEXT01.pdf

Rezanejad, A., \& Rezaei, S. (2013). Academic dishonesty at universities: The case of plagiarism among Iranian language students. Journal of Academic Ethics, 11(4), 275-295.

Riasati, M. J., \& Rahimi, F. (2013). Why do Iranian postgraduate students plagiarize? A qualitative investigation. Middle-East Journal of Scientific Research, 14(3), 309-317.

Sapp, D. A. (2002). Towards an international and intercultural understanding of plagiarism and academic dishonesty in composition: Reflections from the People's Republic of China. Issues in Writing, 13(1), 58-79.

Sowden, C. (2005). Plagiarism and the culture of multilingual students in higher education abroad. ELT Journal, 59(3), 226-233.

Sun, Y.-C. (2009). Using a two-tier test in examining Taiwan graduate students' perspectives on paraphrasing strategies. Asia Pacific Education Review, 10(3), 399-408.

Sutherland-Smith, W. (2003, November). The right to own: TESOL and legal perspectives on plagiarism and the Internet. Paper presented at the International Conference on Language, Education and Diversity, Hamilton, New Zealand.

Sutherland-Smith, W. (2005). Pandora's box: Academic perceptions of student plagiarism in writing. Journal of English for Academic Purposes, 4(1), 8395.

Tahriri, A., \& Eslam-Navaz, H. (2014). Perceptions of EFL graduate students of physical education toward plagiarism. International Journal of Language Learning and Applied Linguistics World (IJLLALW), 5(2), 594604.

Wheeler, G. (2009). Plagiarism in the Japanese universities: Truly a cultural matter? Journal of Second Language Writing, 18(1), 17-29. 
Wilkinson, J. (2009). Staff and student perceptions of plagiarism and cheating. International Journal of Teaching and Learning in Higher Education, 20(2), 98-105.

Yazici, A., Yazici, S., \& Erdem, M. S. (2011). Faculty and student perceptions on college cheating: Evidence from Turkey. Educational Studies, 37(2), $221-231$.

Zafarghandi, A. M., Khoshroo, F., \& Barkat, B. (2012). An investigation of Iranian EFL Masters students' perceptions of plagiarism. International Journal for Educational Integrity, 8(2), 69-85. 